\title{
Prevalence and detection of frailty syndrome in the elderly at Hospital General de México "Dr. Eduardo Liceaga"
}

\author{
Alejandro J. García-Delgado*, Leonor E. Zapata-Altamirano, Iván A. Andrade-Montoya, \\ Aramara Y. Aco-Flores, Ana K. López-Retamoza, and Alejandro Velásquez Sarria \\ Geriatrics Service, Hospital General de México “Dr. Eduardo Liceaga”, Mexico City, Mexico
}

\begin{abstract}
Background: Frailty syndrome is a state of greater vulnerability manifesting with functional impairment, dependence, and mortality. For its study, it has been used the Fried model. The prevalence found in the same hospital in studies of 1998 and 2015 was $16.5 \%$ and $31.2 \%$. We propose to determine the current prevalence using the model proposed by Fried. Materials and methods: A descriptive, cross-sectional, and retrospective study was performed in the Hospital General de México, with 109 participants above 70 years old. Demographic, antrophometric, comorbidities, and functionality data were obtained. Modified Fried criteria were used for classification. The index of Katz and Lawton and Brody was used to assess the basic and instrumental activities of daily living. For statistical analysis, the software SPSS-24 was used. Results: The mean age was 80 years and standard deviation $\pm 5.63,74.1 \%$ (83 patients) were female. Comorbidities were registered in 86.6\%. About 92\% obtained Katz A classification, 5.3\% Katz B, and 1.7\% Katz C. In the Lawton and Brody index, 86.6\% were found to be independent. About $14.3 \%$ were classified as non-frail, $50 \%$ as pre-frail, and $35.7 \%$ as frailty. Conclusions: We determined a prevalence of $35.7 \%$, being $28 \%$ greater than the one reported by Fried et al., and $20 \%$ and $6 \%$ greater than the reported in the studies of 1998 and 2015 in the same hospital. Given that it is possible to recover from fragile to pre-frail, this knowledge will serve to design strategies for the benefit of the patients.
\end{abstract}

Key words: Frailty. Frail. Syndrome. Elderly.

\section{Introduction}

The World Health Organization has recognized that, for the first time in the history of humanity, there will be 1.5 billion people $\geq 65$ years old. Similarly, in Mexico, statistics show the population's rapid aging, by 2015, the aging index being 38.0 for every person of $\geq 60$ years old among 100 children and young. Particularly, in Mexico City, the index was 71.7. A consequence of such epidemiologic transition, alongside aging itself, is a major risk for illness and prevalence of geriatric syndromes, manifesting a greater functional impairment, dependence, and mortality ${ }^{1,2}$.

Frailty syndrome is defined as a state of greater vulnerability secondary to an impaired resolution to homeostasis after a stressing event. It is a disorder that implies multiple intertwined physiological indexes, with a gradual diminution of the physiological reserve, as expected in the elderly, but in an accelerated fashion and with a rapid onset of failure of those homeostatic physiological

\section{Correspondence:}

*Alejandro J. García-Delgado E-mail: jahen_igar@ @otmail.com

0185-1063/@ 2019 Sociedad Médica del Hospital General de Mexico. Published by Permanyer. This is an open access article under the CC BY-NC-
Available online: $21-04-2020$

Rev Med Hosp Gen Mex. 2020:83(2):59-65 www.hospitalgeneral.mx ND license (http://creativecommons.org/licenses/by-nc-nd/4.0/) 
mechanisms, which are determined by genetic and environmental factors, combined with epigenetic mechanisms that could be especially important in the aging process, thus conditioning an adverse prognosis ${ }^{3-6}$.

One of the main frailty study models is the phenotypic one proposed by Fried et al., who established five variables: unintentional loss of weight, self-reported exhaustion and/or fatigue, low level of physical activity, delay in walking speed, and a decrease in muscle strength. Those who scored three or more were considered frail; one or two, pre-frail and those with none of these variables were considered non-frail or robust. Follow-up evaluations included falls, mobility, functionality, hospitalizations, and death, with more adverse results in those persons categorized as frailty?

Besides the one proposed by Fried, there are other study models for frailty syndrome. This lack of consensus about which model should be used for diagnosis sets limited and diverse data about the prevalence of frailty syndrome in the elderly. By performing studies of these geriatric syndrome allows us to know what are the long-term care necessities for the elderly and to assess the repercussions on health costs for the patients, their families, and the health systems. To know the prevalence and to prevent or treat, the frailty has become a priority in the world, with the intention to reduce the level of dependence, institutionalization, long-term assistance necessity and the medical and social costs that these clinical condition arises.

In worldwide population studies, the frailty prevalence varies from $4.9 \%$ to $27.3 \%{ }^{4}$. In the population studied by Fried, $7 \%$ was classified as frailty, $47 \%$ as pre-frail, and $46 \%$ as non-frail (or robust) ${ }^{7}$. In Latin America, the prevalence of frailty syndrome ranges from $30 \%$ to $48 \%$ in women and $21 \%$ to $35 \%$ in men $^{8,9}$. In Mexico, the prevalence has been estimated to be $39 \%$ in the general population, $45 \%$ in women, and $30 \%$ in men ${ }^{8}$. Other studies published in Mexico have found a prevalence of up to $87 \%$ for seniors of more than 65 years old in Family Medicine Units of the Mexican Institute of Social Security ${ }^{10}$. A cross-sectional study conducted in Mexico City that associated frailty with health-linked quality of life found a prevalence of $12.7 \%$ frailty, $38.9 \%$ pre-frail, and $48.4 \%$ non-frail ${ }^{11}$.

In the Hospital General de México "Dr. Eduardo Liceaga," two previous studies performed in 1998 and 2015 reported prevalences of $16.5 \%$ and $31.2 \%$, respectively, with frailty syndrome in the elderly going to ambulatory consultation ${ }^{12,13}$. We propose to determine the current prevalence using the model proposed by Fried.
Table 1. Modified Fried criteria for frailty syndrome

\begin{tabular}{|l|l|}
$\begin{array}{l}\text { Unintentional weight } \\
\text { loss }\end{array}$ & $\begin{array}{l}\text { Unintentional weight loss } \geq 3 \mathrm{Kg} \text { in the } \\
\text { last year or } \mathrm{BMI}<21 \mathrm{Kg} / \mathrm{m}^{2}\end{array}$ \\
\hline Decreased strength & $\begin{array}{l}\text { Referred by the patient in response to } \\
\text { the question of the CES-D depression } \\
\text { questionnaire: in the last week, how } \\
\text { often have you felt that everything you } \\
\text { do requires an effort or that you cannot } \\
\text { continue? }\end{array}$ \\
\hline $\begin{array}{l}\text { Decreased walking } \\
\text { speed }\end{array}$ & $\begin{array}{l}\text { Walking time/4 m. } 20 \% \text { slower (by } \\
\text { gender and height) } \\
\text { Men: }\end{array}$ \\
$\begin{array}{l}\text { Height } \leq 159 \mathrm{~cm} \text { : time } \geq 4.9 \mathrm{~s} \\
\text { Height }>159 \mathrm{~cm} \text { : time } \geq 6,5 \mathrm{~s} \\
\text { Women: } \\
\text { height } \leq 153,7 \mathrm{~cm} \text { : time } \geq 6,5 \mathrm{~s} \\
\text { height }>153,7 \mathrm{~cm} \text { : time } \geq 7,0 \mathrm{~s}\end{array}$ \\
\hline Self-reported fatigue & $\begin{array}{l}\text { Unable to get up from a chair without } \\
\text { using the arms, in correlation to grasp } \\
\text { strength }\end{array}$ \\
\hline $\begin{array}{l}\text { Decreased physical } \\
\text { activity }\end{array}$ & $\begin{array}{l}\text { Referred by the patient in response to } \\
\text { the question: do you perform activities } \\
\text { such as daily walking, gardening, or } \\
\text { some sport once a week? }\end{array}$ \\
\hline
\end{tabular}

Frailty: three or more criteria; pre-frail: 1 or 2 criteria; Robust: zero criteria; $\mathrm{BMI}$ : body mass index.

\section{Materials and methods}

A descriptive, cross-sectional, observational, and retrospective study was performed in the Hospital General de México "Dr. Eduardo Liceaga." Both male and female senior patients above 70 years old who attended to the ambulatory clinic and the Dayroom of the Geriatrics Department were enrolled. The size of the population was 109 , based on previously reported prevalence in a pilot study performed in the same hospital ${ }^{14}$.

Seniors who agreed to participate signed an informed consent form. We included seniors above 70 years old who attended to ambulatory consultation and the Dayroom of Geriatrics Department at Hospital General de México "Dr. Eduardo Liceaga," from January 2014 to December 2015; we excluded those who were unable to walk independently or needed assistance as well as those who had a moderate or severe neurocognitive impairment diagnosis.

An integral geriatric assessment was performed in each participant; demographic, anthropometric, comorbidities, and functionality data were obtained. Modified Fried criteria were used for the initial classification in robust, pre-frail, and frailty (Table 1). We considered frailty those who met three or more criteria, pre-frail 1 
or 2 criteria, and non-frail or robust those with no criteria at all.

Age was registered in years old to the date of data collection. Gender was male or female, according to their phenotypic traits. Weight was measured in a calibrated medical scale, with the patient wearing only the hospital gown. Height was registered with stadiometer for adults, placing the patient in a standing position, with no shoes, head uncovered, the back against the stadiometer, head, shoulders, hips, and heels held together and the tips separated, forming a $45^{\circ}$ angle. Arms are hanging loose and downward to both sides of the body: steady head, and eyes gazing to front. Height was measured in meters with decimals. Body mass index (BMI) was calculated according to the formula $\mathrm{BMI}=$ (weight in kilograms) $\div$ (height in meters) ${ }^{2}$.

Katz index evaluated activities of daily living and was estimated qualitatively to the degree of level of independence of the patient. Six daily activities were studied. The Katz index ranges eight possible scores: (A) independent in all functions; (B) independent in all functions except one; (C) independent in all functions except bathing and any other; (D) independent in all functions except bathing, dressing and any other; (E) independent in all functions except bathing, dressing, toilet, and any other, (F) independent in all functions except bathing, dressing, toilet, mobility, and any other of the two remaining; $(G)$ dependent in all functions, and $(\mathrm{H})$ dependent in at least two functions but no classifiable as C, D, E, or F.

The instrumental activities of daily living were evaluated with the Lawton and Brody index. This index consists of eight items; each item has a number assigned. The total score is the sum of all responses and ranges from 0 (maximum dependence) to 8 (total independence). The considered activities are the capacity for using the telephone, transportation, medication, finances, shopping, cooking, household chores, and laundry. Five is considered a cutting point 5-8: independence and 0-4: dependence.

The presence of chronic diseases was registered, such as diabetes mellitus type 2, hypertension, ischemic cardiopathy, chronic lung disease, and osteoarthrosis, considering presence or absence of comorbidities. It was evaluated if the patient used some assistance tool for deambulation such as a cane or adult walker.

We used SPSS-24 software for statistical analysis. It was an investigation with minimal risk, according to the General Law of Health regarding Health Investigation, given that the data were obtained by means of common
Table 2. Population's sociodemographic and clinical characteristics

\begin{tabular}{|l|c|}
\hline Variables & Values \\
\hline Total & $112(100 \%)$ \\
\hline Age in years (mean \pm SD) & $80( \pm 5.63)$ \\
\hline Female $\mathrm{n}(\%)$ & $83(74.11 \%)$ \\
\hline BMI (mean \pm SD) & $26.77( \pm 4.01)$ \\
\hline Comorbidities $\mathrm{n}(\%)$ & $97(86.6 \%)$ \\
\hline Katz $\mathrm{n}(\%)$ & \\
$\mathrm{A}$ & $104(92.86 \%)$ \\
\hline B & $6(5.36 \%)$ \\
$\mathrm{C}$ & $2(1.79 \%)$ \\
\hline Lawton and Brody & \\
Independent & $97(86.61 \%)$ \\
Dependent & $15(13.39 \%)$ \\
\hline Walking seconds (mean \pm SD) & $6.12( \pm 3.47)$ \\
\hline Velocity m/s (mean \pm SD) & $1.19( \pm 1.03)$ \\
\hline Assistance tool $\mathrm{n}(\%)$ & $32(28.57 \%)$ \\
\hline
\end{tabular}

BMI: body mass index; SD: standard deviation.

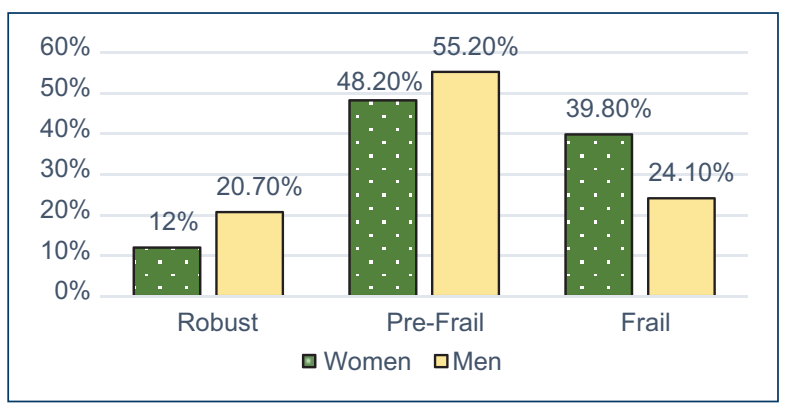

Figure 1. Prevalence of frailty phenotypes by gender.

procedures: medical chart, physical examination, and geriatric clinical scales.

\section{Results}

A total of 112 patients were enrolled, all of them participated in the analysis. The study was descriptive and cross-sectional. The mean age was 80 years old, with a standard deviation (SD) of \pm 5.63 . The minimum age was 70 years old and maximum age was 94 years old. About $74.1 \%$ (83 patients) were female. Mean BMI was 26.7 with a SD of \pm 4.01 .

The presence of one or more comorbidities such as type 2 diabetes mellitus, hypertension, ischemic cardiopathy, chronic obstructive pulmonary disease, chronic cardiac insufficiency, or asteoarthrosis was registered 


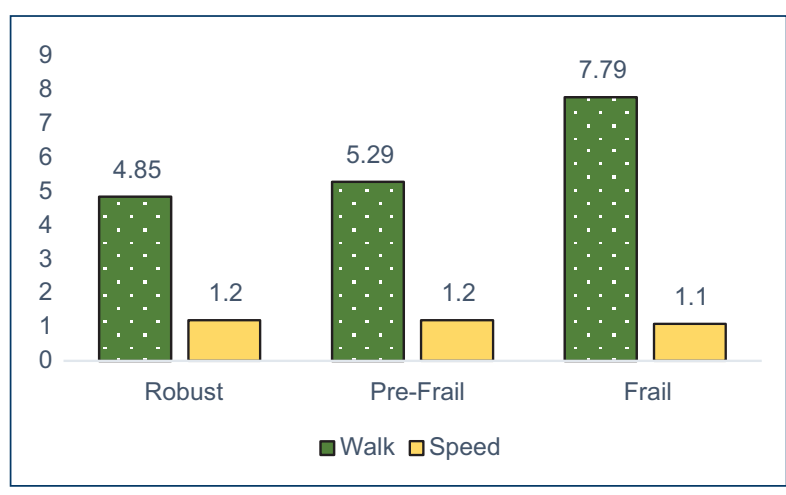

Figure 2. Average walk (time in seconds to travel $4 \mathrm{~m}$ ) and speed (walk/4) according to the classification of frailty phenotypes.

in $86.6 \%$ of the population. The sociodemographic and clinical characteristics are described in table 2.

Out of the total population, $14.3 \%$ was classified as non-frail, $50 \%$ as pre-frail, and $35.7 \%$ as frailty. As for gender, $24.1 \%$ of men and $39.8 \%$ of women were classified as frailty (Fig. 1). BMI was 27 in the robust, 26.8 in pre-frail, and 26.5 in the frailty. Comorbidities were found in $14 \%$ of non-frail and $36.1 \%$ in frailty. The number of comorbidities was $1.69,1.59$, and 1.75 , respectively, in the same groups.

In evaluating functionality, it was found that $14.4 \%$ of the robust, $51 \%$ of the pre-frail, and $34.6 \%$ of the frailty had a Katz A score. Katz B scores were found in 16.7\%, $33.3 \%$, and $50 \%$, in the same order. Classification in the Lawton and Brody index resulted in independent for $16.5 \%, 52.6 \%$, and $30.9 \%$ of the robust, pre-frail, and frailty, respectively. Regarding the $4 \mathrm{~m}$ walking test, the meantime for the robust was $4.85 \mathrm{~s}, 5.29 \mathrm{~s}$ for the pre-frail, and $7.79 \mathrm{~s}$ for the frailty. The calculated speed for each group was $1.2 \mathrm{~m} / \mathrm{s}$ in the robust and pre-frail, and $1.1 \mathrm{~m} / \mathrm{s}$ in the frailty (Fig. 2). Usage of an assistance tool for walking was $6.3 \%$ in the robust and $46.9 \%$ in the pre-frail and frailty.

As for the variables comprising the frailty syndrome in the fragile group, the findings showed unintentional loss of weight in $72 \%$, decreased strength in $54 \%$, decreased walking speed in $71.9 \%$, self-reported fatigue in $96.3 \%$, and, finally, reduced physical activity in $52.7 \%$. None of the robust met any criterion (Table 3).

\section{Discussion}

The prevalence of frailty in the total population of this study was $35.7 \%$, almost $28.7 \%$ more than the prevalence reported by Fried ${ }^{7}$. Nonetheless, the prevalence is more similar to the one reported in Latin America, between $21 \%$ and $48 \%$, being $8 \%$ more compared with the prevalence reported by Runzer-Colmenares et al. ${ }^{15}$, who used the modified Fried criteria, the same in this investigation. Set side by side with the prevalence in Mexico, the numbers are similar to the ones in this investigation, $39 \%$ versus $35 \%{ }^{15-18}$.

In comparison with the previous studies conducted in the Hospital General de México, the results are 20\% and $6 \%$ more than the investigations of 1998 and 2015, repectively ${ }^{12,13}$. However, none of them used the Fried nor the modified Fried criteria.

The wide variability in respect to international studies is related to social and even more economic differences. It is relevant to mention that this variability is also related to the tool used for this investigation, biomedical factors, and different to other criteria such as the one proposed by Rockwood that includes psychosocial and environmental factors ${ }^{4}$; also different is the SHARE-FI scale in Spanish primary care for non-institutional patients; other scales: FRAIL, Tilburg Frailty Indicator, or Groningen Frailty Indicator ${ }^{19,20}$.

In regard to gender, frailty prevalence was more frequent in women than in men, $39.8 \%$ versus $24.1 \%$; this matches the Gale, Cooper, and Sayer study ${ }^{21}$ that used Fried criteria, in which prevalence was $16 \%$ in women and $12 \%$ in men. Similarly, frailty prevalence for Latin America ranged from $30 \%$ to $48 \%$ in women and $21 \%$ to $35 \%$ in men $^{9}$. Finally, it goes together with the prevalence reports from Mexico with $45 \%$ in women and $30 \%$ in men $^{8}$. In the present study, there was a nonsignificant $p(0.24)$ for gender, thus showing no relationship between prevalence and gender. Garcia-Gonzalez et al. ${ }^{16}$ conducted a study in Mexican population in which frailty index was significantly higher in women in groups $<80$ years old. It is relevant to emphasize that women represented $74.11 \%$ of the studied population, which could have been a factor that inclined for that higher index in women.

Association between BMI and frailty has been studied several times with different results; some suggest that pre-frail and frailty elderly have lower BMI values ${ }^{22}$. However, there have also been reported higher BMI values associated with frailty ${ }^{23}$. In this study, BMI was $26.5 \pm$ 4.7 in the fragile, the patients being classified with overweight, and despite there was no statistical difference between the evaluated groups, there is correspondence with another findings reported in Latin population where higher BMI values are associated with a higher probability for frailty ${ }^{9,24}$. In this fashion, it is evident that the results with $\mathrm{BMI}$ are not the best way to evaluate the 
Table 3. Comparison between sociodemographic and clinical characteristics according to frailty diagnosis

\begin{tabular}{|c|c|c|c|c|}
\hline Variables & Non-frail & Pre-frail & Frailty & $\mathrm{p}$ value \\
\hline Total n (\%) & 16 (14.3) & $56(50)$ & $40(35.7)$ & \\
\hline $\begin{array}{l}\text { Gender n (\%) } \\
\text { Women } \\
\text { Men }\end{array}$ & $\begin{array}{l}10(12) \\
6(20.7)\end{array}$ & $\begin{array}{l}40(48.2) \\
16(55.2)\end{array}$ & $\begin{array}{c}33(39.8) \\
7(24.1)\end{array}$ & $0.24^{\mathrm{a}}$ \\
\hline Mean age $( \pm S D)$ & $81( \pm 4.5)$ & $80( \pm 5.8)$ & $80( \pm 5.7)$ & $0.81^{\mathrm{b}}$ \\
\hline BMI & $27.0( \pm 3.2)$ & $26.8( \pm 3.6)$ & $26.5( \pm 4.7)$ & $0.91^{\mathrm{b}}$ \\
\hline $\begin{array}{l}\text { Comorbidities } \\
\text { Yes }(\%) \\
\text { No }(\%) \\
\text { \# of comorbidities }\end{array}$ & $\begin{array}{c}14(14.4) \\
2(13.3) \\
1.69( \pm 1.01)\end{array}$ & $\begin{array}{c}48(49.5) \\
8(53.3) \\
1.59( \pm 1.02)\end{array}$ & $\begin{array}{c}35(36.1) \\
5(33.3) \\
1.75( \pm 1.12)\end{array}$ & $\begin{array}{l}0.96^{\mathrm{a}} \\
0.76^{\mathrm{b}}\end{array}$ \\
\hline $\begin{array}{l}\text { Katz }(\%) \\
\text { A } \\
\text { B } \\
\text { C }\end{array}$ & $\begin{array}{c}15(14.4) \\
1(16.7) \\
0(0)\end{array}$ & $\begin{array}{c}53(51.0) \\
2(33.3) \\
1(50)\end{array}$ & $\begin{array}{c}36(34.6) \\
3(50) \\
1(50)\end{array}$ & $0.88^{\mathrm{a}}$ \\
\hline $\begin{array}{l}\text { Lawton and Brody (\%) } \\
\text { Independent } \\
\text { Dependent }\end{array}$ & $\begin{array}{c}16(16.5) \\
0(0)\end{array}$ & $\begin{array}{c}51(52.6) \\
5(33.3)\end{array}$ & $\begin{array}{l}30(30.9) \\
10(66.7)\end{array}$ & $0.018^{a}$ \\
\hline Walking & $4.85( \pm 0.74)$ & $5.29( \pm 2.9)$ & $7.79( \pm 4.1)$ & $<0.001^{\mathrm{b}}$ \\
\hline Speed & $1.20( \pm 0.19)$ & $1.20( \pm 1.05)$ & $1.1( \pm 1.2)$ & $0.98^{\mathrm{b}}$ \\
\hline $\begin{array}{l}\text { Assistance tool (\%) } \\
\text { Si } \\
\text { No }\end{array}$ & $\begin{array}{c}2(6.3) \\
14(17.5)\end{array}$ & $\begin{array}{l}15(46.9) \\
41(51.3)\end{array}$ & $\begin{array}{l}15(46.9) \\
25(31.3)\end{array}$ & $0.15^{\mathrm{a}}$ \\
\hline $\begin{array}{l}\text { Weight loss }(\%) \\
\text { Si } \\
\text { No }\end{array}$ & $\begin{array}{c}0(0) \\
16(18.4)\end{array}$ & $\begin{array}{c}7(28) \\
49(56.3)\end{array}$ & $\begin{array}{c}18(72) \\
22(25.3)\end{array}$ & $<0.001^{\mathrm{a}}$ \\
\hline $\begin{array}{l}\text { Decreased strength }(\%) \\
\text { Si } \\
\text { No }\end{array}$ & $\begin{array}{c}0(0) \\
16(32.7)\end{array}$ & $\begin{array}{c}29(46) \\
27(55.1)\end{array}$ & $\begin{array}{l}34(54) \\
6(12.2)\end{array}$ & $<0.001^{\mathrm{a}}$ \\
\hline $\begin{array}{l}\text { Decreased walking speed }(\%) \\
\text { Si } \\
\text { No }\end{array}$ & $\begin{array}{c}0(0) \\
16(20)\end{array}$ & $\begin{array}{c}9(28.1) \\
47(58.8)\end{array}$ & $\begin{array}{l}23(71.9) \\
17(21.3)\end{array}$ & $<0.001^{\mathrm{a}}$ \\
\hline $\begin{array}{l}\text { Self-reported fatigue (\%) } \\
\text { Si } \\
\text { No }\end{array}$ & $\begin{array}{c}0(0) \\
16(18.8)\end{array}$ & $\begin{array}{c}1(3.7) \\
55(64.7)\end{array}$ & $\begin{array}{l}26(96.3) \\
14(16.5)\end{array}$ & $<0.001^{\mathrm{a}}$ \\
\hline $\begin{array}{l}\text { Decreased physical activity (\%) } \\
\mathrm{Si} \\
\text { No }\end{array}$ & $\begin{array}{c}0(0) \\
16(42.1)\end{array}$ & $\begin{array}{c}35(47.3) \\
21(55.3)\end{array}$ & $\begin{array}{c}39(52.7) \\
1(2.6)\end{array}$ & $<0.001^{\mathrm{a}}$ \\
\hline
\end{tabular}

aChi-square distribution; ${ }^{\mathrm{b} A N O V A .}$

nutritional state of the patients and its relation with frailty. Nowadays, we can study the nutritional state by bioelectrical impedance, a more sensitive method to measure body composition that translates the nutritional state, more useful than BMI for frailty diagnosis ${ }^{25}$.

The presence of comorbidities was $36 \%$ in the frailty, and the average of comorbidity was $1.75 \pm 1.12$ in the same group. However, comorbidity presence was more frequent in the pre-frail group, with $49 \%$. It is well known that the presence of multiple diseases is more frequent at advanced ages, according to the Survey of Health,
Well-Being and Aging in Latin America and the Caribbe$\mathrm{an}^{26}$, which showed that $34.1 \%$ of the elderly suffer from two or more chronic diseases. It has been described the relation of frailty with physiopathological mechanisms and epidemiological characteristics of diseases, especially the chronic ones ${ }^{27}$. In contrast to findings by Fried et al. ${ }^{7}$, which showed an association between moderate and severe comorbidity of the Charlson scale and the frailty phenotype, in the present study, we did not find the foretold association, probably due to the fact that comorbidity was categorized only as present or absent. 


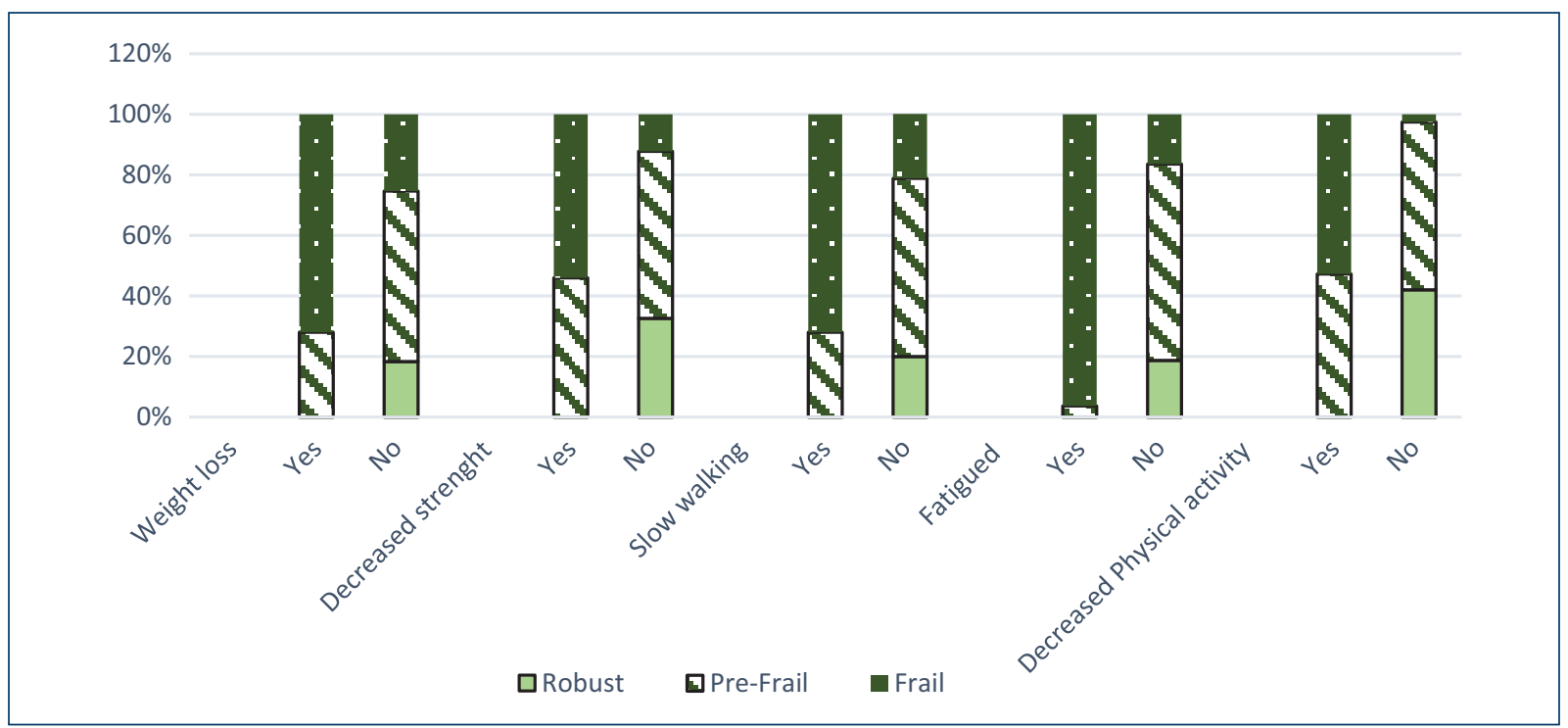

Figure 3. Prevalence of modified Fried criteria in the study population.

According to the Katz index applied in this population, just $A, B$, and $C$ categories were found, and there was no significant statically association with frailty syndrome. In a study conducted by Sousa and dos Santos ${ }^{28}, 11.4 \%$ was found to be frailty for daily activities. In our study, exclusion criteria were patients uncapable of walking independently or with the need of assistance, moderate, or severe dementia, which categorized our population in Katz A, B, and some $\mathrm{C}$. Nonetheless, when considering the Lawton and Brody index, $30 \%$ of the fragile were classified as independent, whereas in the study by de Sousa and dos Santos it was $7.3 \%$. In that sense, statistical significance was found $(p=0.018)$, suggesting that the inability to perform instrumental activities of daily living predicts frailty syndrome in the elderly. In Mexico, Sánchez-García et al. ${ }^{29}$ found that $45 \%$ and $47 \%$ of their population presented one or more inabilities in the basic and instrumental activities scales, respectively.

In the walking test, it was found that the frailty traveled $4 \mathrm{~m}$ with a meantime of $7.79 \pm 4.1 \mathrm{~s}$, showing a statistical significance $(p<0.001)$ in comparison with the other groups, the meantimes being $5.29 \pm 2.9$ and $4.85 \pm 0.74$ $s$ for the pre-frail and non-frail, respectively. In the study by Sánchez-García et al. ${ }^{29}$, with Mexican population, walking speed was $6.6 \pm 0.2$ for women and $3.6 \pm 0.2$ for men. In the study by Runzer-Colmenares et al. ${ }^{15}$, the group classified as frailty had a walking velocity of $8.3 \pm$ 6.1 , also showing the statistical difference with the other groups within the population. However, in categorizing the patients calculating their velocity (walking/4) to obtain the meters/seconds traveled, this significance is lost. We can conclude that the walking test categorizes differences between individuals, whereas walking velocity, a standard measurement, translates the behavior as a group.

In our study, probably in association with the functional characteristics of the population, the usage or not usage of assistance tools for deambulation appears to be of little significance for frailty diagnosis, at least for the basic activities of daily life.

Finally, when evaluating the variables, we used to calculate the frailty phenotype according to the modified Fried criteria, each one of them resulted to be statistically significant for the classification of frailty in this population, being the expected result, for those were the variables directly involved for the diagnosis. In decreasing order, the most frequent variables for the frailty diagnosis were: self-reported fatigue $96.3 \%$, unintentional loss of weight $72 \%$, decreased walking speed $71 \%$, decreased strength $54 \%$, and decreased physical activity $52.7 \%$ (Fig. 3).

\section{Conclusions}

Frailty prevalence was $35.7 \%$ in the elderly $\geq 70$ years old that attended to ambulatory consultation and to the Dayroom of Geriatrics Department at the Hospital General de México "Dr. Eduardo Liceaga," using the modified Fried criteria. In this same population and according to the phenotypic categorization of the frailty syndrome, the prevalence of patients classified as robust, pre-frail, and frailty was $14.3 \%, 50 \%$, and $37.7 \%$, respectively. 
In comparison with fragility prevalence reported by other studies, it was $28 \%$ more than the one reported by Fried et al. 7 , being more similar to the one reported in Latin America, between 21 and $48 \%$, and the ones in Mexico of $39 \%$. Finally, $8 \%$ more than the one reported by Runzer-Colmenares et al. ${ }^{15}$, who used, specifically, the same criteria that we used for this study. Comparing with previous studies carried on in the Hospital General de México, they are 20\% and 6\% more than the investigations of 1998 and 2015, respectively, although in those studies, it was not used the Fried nor the modified Fried criteria for the classification.

Considering the high prevalence of this syndrome in the population of elderly and that it has been demonstrated the ability to recover from frailty to pre-frail by means of medication, nutrition, and physical exercise (and as preventive measures), its diagnosis and awareness of the current prevalences are tools to design, look for and project plans in benefit of quality of life and functionality of our patients.

\section{Acknowledgments}

We thank the participants for their involvement in the study.

\section{Conflicts of interest}

The authors declare that they have no conflicts of interest.

\section{Ethical disclosure}

Protection of human and animal subjects. The authors declare that no experiments were performed on humans or animals for this investigation.

Confidentiality of data. The authors declare that they have followed the protocols of their work center on the publication of patient data.

Right to privacy and informed consent. The authors have obtained the written informed consent of the patients or subjects mentioned in the article. The corresponding author is in possession of this document.

\section{References}

1. Solfrizzi V, Scafato E, Frisardi V, Sancarlo D, Seripa D, Logroscino G, et al. Frailty syndrome and all-cause mortality in demented patients: the Italian longitudinal study on aging. Age (Dordr). 2012;34:507-17.

2. Buckinx F, Rolland Y, Reginster JY, Ricour C, Petermans J, Bruyère $O$. Burden of frailty in the elderly population: perspectives for a public health challenge. Arch Public Health. 2015;73:19.
3. Bergman H, Ferrucci L, Guralnik J, Hogan DB, Hummel S, Karunananthan $S$, et al. Frailty: an emerging research and clinical paradigm-issues and controversies. J Gerontol A Biol Sci Med Sci. 2007;62:731-7.

4. Clegg A, Young J, lliffe S, Rikkert MO, Rockwood K. Frailty in elderly people. Lancet. 2013;381:752-62.

5. McMillan GJ, Hubbard RE. Frailty in older inpatients: what physicians need to know. QJM. 2012;105:1059-65.

6. Rodríguez-Mañas L, Féart C, Mann G, Viña J, Chatterji S, Chodzko-Zajko W, et al. Searching for an operational definition of frailty: a Delphi method based consensus statement: the frailty operative definition-consensus conference project. J Gerontol A Biol Sci Med Sci. 2013;68:62-7.

7. Fried LP, Tangen CM, Walston J, Newman AB, Hirsch C, Gottdiener J, et al. Frailty in older adults: evidence for a phenotype. J Gerontol A Biol Sci Med Sci. 2001;56:M146-56

8. Secretaria de Salud. Diagnóstico y Tratamiento del Síndrome de Fragilidad en el Adulto Mayor. México: Centro Nacional de Excelencia Tecnológica en Salud; 2014.

9. Alvarado BE, Zunzunegui MV, Béland F, Bamvita JM. Life course social and health conditions linked to frailty in Latin American older men and women. J Gerontol A Biol Sci Med Sci. 2008;63:1399-406.

10. Soto L. Prevalencia del Síndrome de Fragilidad en Adultos Mayores a 65 Años en la UMF 21 del IMSS, (Tesis de Posgrado). Ciudad de México: Universidad Nacional Autónoma de México; 2013.

11. Moreno M. Asociación Entre Fragilidad y Calidad de Vida en Una Cohorte de Ancianos de la Ciudad de México, (Tesis de Posgrado). Ciudad de México: Universidad Nacional Autónoma de México; 2011.

12. Jiménez A. Incidencia y Prevalencia del Síndrome de Fragilidad en la Clínica de Geriatría del Hospital General de México, (Tesis de posgrado). Ciudad de México: Universidad Nacional Autónoma de México; 1998.

13. Silva A. Fragilidad en el Adulto Mayor de la Consulta Externa del Hospital General de México, (Tesis de Posgrado). Ciudad de México: Universidad Nacional Autónoma de México; 2015.

14. Aco A, Velasquez A, López AK, Zapata L. Prevalencia de Fragilidad en Pacientes Ambulatorios en un Tercer Nivel de Atención. $3^{\text {rd }}$ Congreso Anual de la Sociedad de Geriatras de México. Ciudad de México; 2014.

15. Runzer-Colmenares FM, Samper-Ternent R, AI Snih S, Ottenbacher KJ, Parodi JF, Wong R. Prevalence and factors associated with frailty among Peruvian older adults. Arch Gerontol Geriatr. 2014;58:69-73.

16. García-González JJ, García-Peña C, Franco-Marina F, Gutiérrez-Robledo LM. A frailty index to predict the mortality risk in a population of senior Mexican adults. BMC Geriatr. 2009;9:47.

17. García T, López J, Villalobos J, D’Hyver C. Prevalencia de síndromes geriátricos en ancianos hospitalizados. Med Int Mex. 2006;22:369-74.

18. del Carmen QE, Antonio ZG, Rosalía AB. Síndrome de fragilidad en adultos mayores no institucionalizados de Emiliano Zapata, Tabasco, México. Univ Méd. 2011;52:255-68.

19. Eugenia PM, Rebollo A, Jiménez J. Fragilidad: ¿cómo podemos detectarla? Enferm Nefrol. 2016;19:170-3.

20. Sutorius FL, Hoogendijk EO, Prins BA, van Hout HP. Comparison of 10 single and stepped methods to identify frail older persons in primary care: diagnostic and prognostic accuracy. BMC Fam Pract. 2016;17:102.

21. Gale CR, Cooper C, Sayer AA. Prevalence of frailty and disability: findings from the English longitudinal study of ageing. Age Ageing. 2015; 44:162-5.

22. Cawthon PM, Marshall LM, Michael Y, Dam TT, Ensrud KE, Barrett-Connor $E$, et al. Frailty in older men: prevalence, progression, and relationship with mortality. J Am Geriatr Soc. 2007;55:1216-23.

23. Blaum CS, Xue QL, Michelon E, Semba RD, Fried LP. The association between obesity and the frailty syndrome in older women: the women's health and aging studies. J Am Geriatr Soc. 2005;53:927-34.

24. Reis W, Oliveira JA, da Silva R, Trindade K, Henrique M. Prefragilidad y fragilidad de ancianos residentes en municipios con bajo índice de desarrollo humano. Rev Lat Am Enfermagem. 2014;22:654-61.

25. Kilic MK, Kizilarslanoglu MC, Arik G, Bolayir B, Kara O, Dogan Varan H, et al. Association of bioelectrical impedance analysis-derived phase angle and sarcopenia in older adults. Nutr Clin Pract. 2017;32:103-9.

26. Menéndez J, Guevara A, Arcia N, León-Díaz EM, Marín C, Alfonso JC. Enfermedades crónicas y limitación funcional en adultos mayores: estudio comparativo en siete ciudades de América Latina y el Caribe. Rev Panam Salud Publica. 2005;17:353-61.

27. Weiss CO. Frailty and chronic diseases in older adults. Clin Geriatr Med. 2011;27:39-52.

28. Sousa M, dos Santos D. Factores asociados al síndrome de fragilidad en ancianos residentes en área urbana. Rev Lat Am Enfermagem. 2014; 22:874-82.

29. Sánchez-García S, Sánchez-Arenas R, García-Peña C, Rosas-Carrasco O, Avila-Funes JA, Ruiz-Arregui $L$, et al. Frailty among community-dwelling elderly Mexican people: prevalence and association with sociodemographic characteristics, health state and the use of health services. Geriatr Gerontol Int. 2014;14:395-402. 